\title{
Acorn non-dormancy disrupts Janzen-Connell effects on temperate white oaks
}

\author{
Yi Xianfeng ${ }^{1}$, Minghui Wang ${ }^{2}$, and Mengyao $\mathrm{Ju}^{3}$ \\ ${ }^{1}$ Henan University of Science and Technolgy \\ ${ }^{2}$ College of Life Sciences \\ ${ }^{3}$ Qufu Normal University
}

June 16, 2020

\begin{abstract}
Although the Janzen-Connell model recognizes high level of predation as the main factor influencing propagule survival close to parent trees, acorns of white oak species germinate immediately after seed fall and might serve as a mechanism to escape this predation. In this study, we investigated the seedling establishment, growth, mortality and recruitment of two co-occurring oak species Quercus variabilis and Q. aliena as a function of distances to conspecific adults, to examine if Janzen-Connell effects necessarily result in Janzen-Connell pattern in temperate white oak forests. Our results showed that the survivorship of 1-year-old seedlings of the two white oak species was negatively correlated with the distances from the parent trees. This pattern of seedling survivorship can largely be explained by rapid germination of white oak acorns in autumn and/or the high regeneration capacity of the robust taproots even after the cotyledons are predated. Recruitment possibility indicated by the 2-year-old seedlings, however, showed an exact compensation pattern, generally reflecting the interaction between high level of seedling establishment and host-specific herbivores under the parent trees. Our results provide evidence that rapid autumn germination of acorns and high regeneration capacity of taproots limit the occurrence of Janzen-Connell effects on seedling survival close to parent trees of white oaks in temperate forests.
\end{abstract}

\section{Hosted file}

Rapid germination of acorns may facilitate seedling survival under-Ecology letters.docx available at https://authorea.com/users/333936/articles/460035-acorn-non-dormancy-disruptsjanzen-connell-effects-on-temperate-white-oaks 